\title{
Equisetum crude drugs: Epidermal Characters for Identification
}

\author{
S. Ölzant, F. Gerngross, R. Länger* \\ Dept. of Pharmacognosy, University Vienna \\ Center of Pharmacy, Althanstraße 14, A - 1090 Vienna, Austria
}

\begin{abstract}
Epidermal characters of nine of the Central European Equisetum species were documented using both scanning electron and light microscopy. The arrangement of silica pilulae on the subsidiary cells of stomata as well as the type and the arrangement of papillae on the ridges of main stems and branches allow an unambiguous identification of the species even in the powdered state. A key for the identification is presented, and recommendations for an improved text for the monograph in the European Pharmacopeia are given.
\end{abstract}

\section{Keywords}

Equisetum, microscopy, SEM, anatomy, identification, adulteration

\section{Introduction}

The unambiguous identification of individuals of the genus Equisetum sometimes is a challenge even when complete herbarium specimens are on hand. Botanical keys [e.g. 1] recommend the preparation of transverse sections of the stems: the proportion of the hollows in the stem in combination with morphological characters of the nodes and leaf sheaths should allow a determination of the species.

In the monograph of Equisetum arvense of the European Pharmacopoeia emphasis is laid on the paracytic stomata with typical ridges of the superimposed subsidiary cells and on U-shaped epidermal cells, which should be discernible in a 
transverse section. Our preliminary investigations revealed that the mentioned characters of the stomata are present in all species of the genus Equisetum. Furthermore the U-shaped epidermal cells are characters of the ridges of the branches, which are typically seen in the surface view. Therefore a revision of the monograph seemed to be appropriate.

The powder of Equisetum arvense mainly consists of non typical parenchyma and vessels. Only the few fragments showing the epidermis with stomata and ridges with papillae ${ }^{1}$ may serve for identification. Promising data are published from investigations using scanning electron microscopy (SEM) [2, 3, 4] or ash preparations $[5,6]$, which focus on silica incrusted pilulae and mamillae. These structures are poorly visible in the light microscope. An attempt for the identification of powdered material was done by Schier [7], he presented a coarse overview of the papillae on the ridges.

In order to provide feasible characters for the proof of identity, the objective of this study was a systematic collection of characters of the stomata, the epidermal cells and of the structure of the ridges of Central European Equisetum species by means of light microscopy with support of SEM, leading to a proposal for the monograph in the European Pharmacopoeia.

\section{Results}

\section{Stomata and epidermis of stem grooves}

Subgenus Hippochaete (E. variegatum, E. hyemale, E. ramosissimum)

The three species are characterized by deepened stomata (app. $30 \mu \mathrm{m}$ below the level of the epidermis), which are arranged mostly in a single exact vertical row at

\section{Definition of terms}

Pilulae: silica incrusted hemispherical or globose bead-like objects, 1-2 $\mu \mathrm{m}$ in diameter and length. Mamillae: Rounded or conical cuticular warts, app. $10 \mu \mathrm{m}$ in diameter, mostly covered with pilulae. Papillae: projections of the cell wall, typically at the ridges of the stems, partly forming horizontal bars reaching the flanks of the grooves. 
each flank of a ridge ( $=2$ single rows between the ridges, examples given in Figs. 1-4). Moreover the surface of the superimposed subsidiary cells is completely smooth. Silica pilulae, which would be discernible as small black dots in the light microscope, are absent. The epidermis between the stomata is nearly planar in $E$. hyemale, only flattish horizontal ridges with few mamillae in the grooves between are present. In E. variegatum and E. ramosissimum conspicuous mamillae are abundant, additionally the latter is densely covered with silica pilulae.

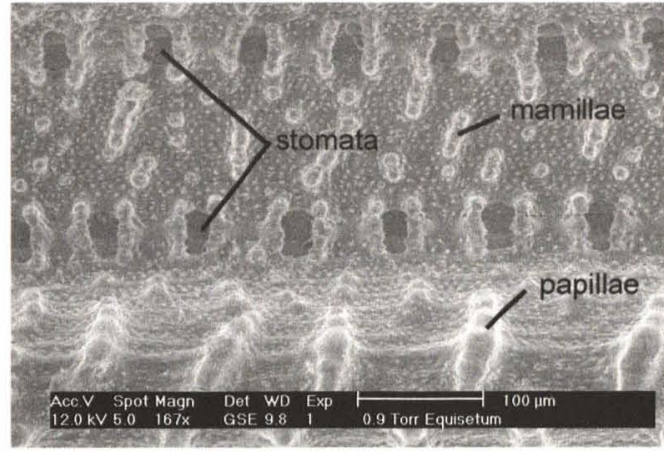

Fig. 1: E. ramosissimum, Stomata arranged in 2 single rows (SEM).

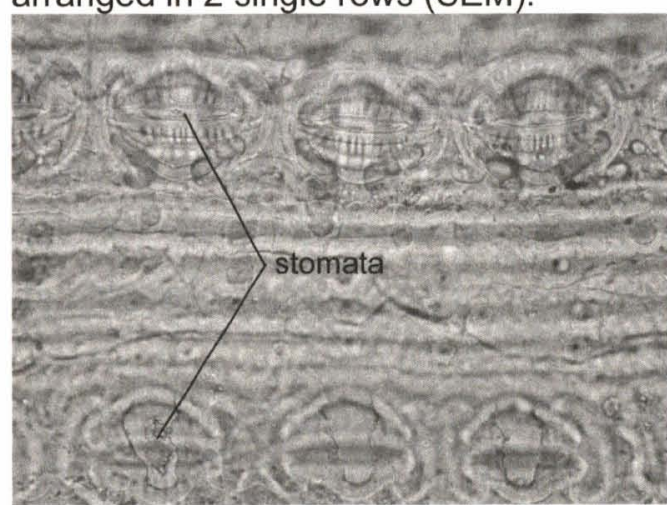

Fig. 3: E. ramosissimum, Stomata arranged in 2 rows (light microscope, objective 20x)

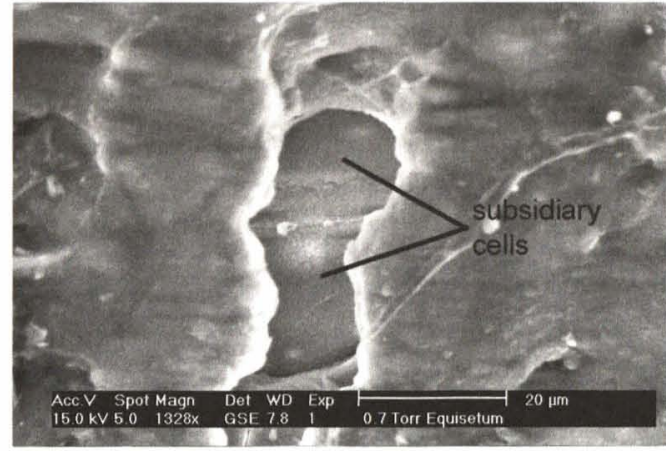

Fig. 2: E. hyemale, deepened stomium with smooth subsidiary cells (SEM).

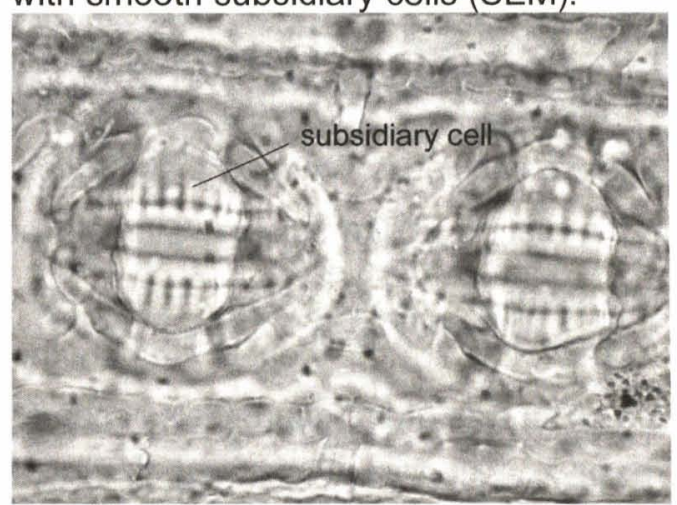

Fig. 4: E. ramosissimum, deepened stomata (light microscope, objective 40x) 
Subgenus Equisetum (E. arvense, E. palustre, E. pratense, E. fluviatile,

E. sylvaticum, E. telmateia)

The subsidiary cells of all investigated species of the subgenus Equisetum are in plane with the epidermal cells. Two main types of distribution of silica pilulae on the subsidiary cells are present:

a) the pilulae form a distinct margin, the area in between is uniformly scattered with smaller pilulae [E. arvense (Fig. 5), E. sylvaticum, E. fluviatile];

b) the pilulae are uniformly scattered, dense at the pore, sometimes getting fewer towards the margin of the subsidiary cell, a distinct margin of pilulae is absent [E. telmateia, E. palustre (Fig. 6), E. pratense]. Although these pilulae are not rich in contrast the arrangement is discernible in the light microscope, too (Fig. 7, 8).

The type of the distribution of silica pilulae on the subsidiary cells is identical on the main stem and on the branches.

On larger fragments in a powder the arrangement of stomata may be discernible. Stomata in a single row or in two close rows per flank in the main stem are characteristic for E. sylvaticum and E. pratense, while in $E$. arvense the stomata occur in rows of (2)-3-4. Stomata in more than 4 axial rows are typical for $E$. palustre, particularly towards the ridges the stomata appear in horizontal rows too. All these species is common that the central part of the grooves is free of stomata. In contrast, in E. fluviatile the stomata are scattered all over the grooves. On the main stem of $E$. telmateia stomata are nearly absent, the branches resemble in respect to the arrangement of stomata those of $E$. arvense.

The size of the guard cells is hardly discernible because of the superimposed subsidiary cells. Their size seems to be too variable within a species to serve as differential character. In surface view in the light microscope the area of ridges in the subsidiary cells is usually larger than the area covered with silica pilulae. The variability of the density of the ridges in the subsidiary cells seems to be too large to serve as character for differentiation. 


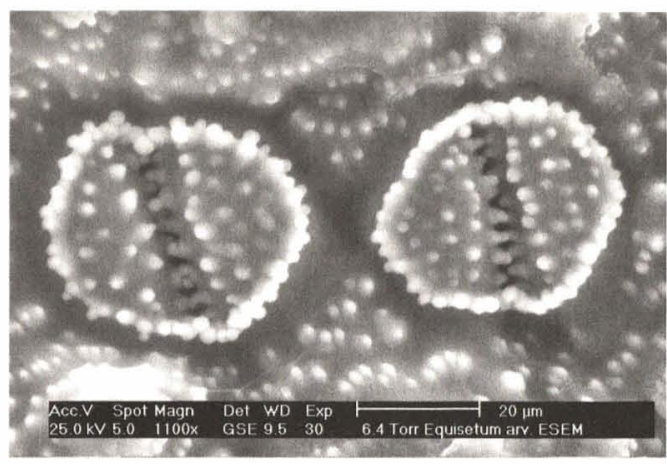

Fig. 5: E. arvense, subsidiary cells with pilulae forming a distinct margin (SEM).

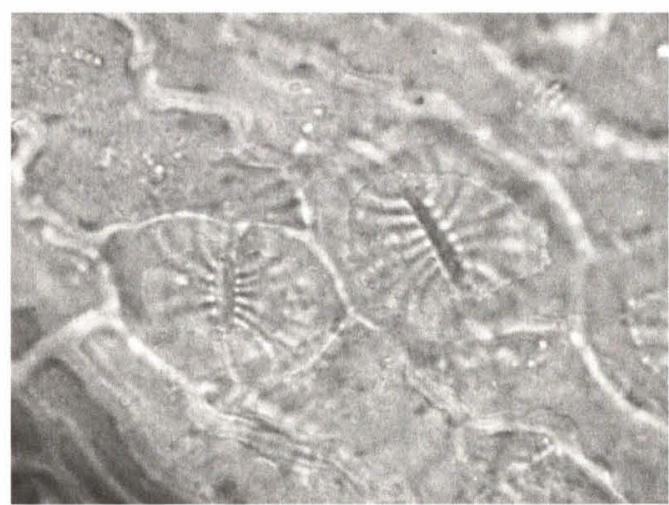

Fig. 7: E. arvense, pilulae forming a margin (light microscope)

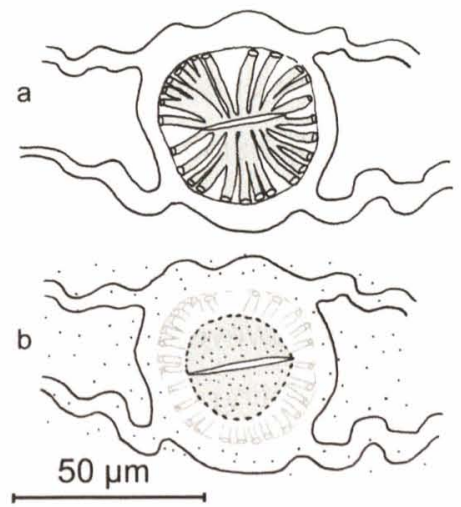

Fig. 9: E. arvense, stomium; a) focus deep; b) focus high

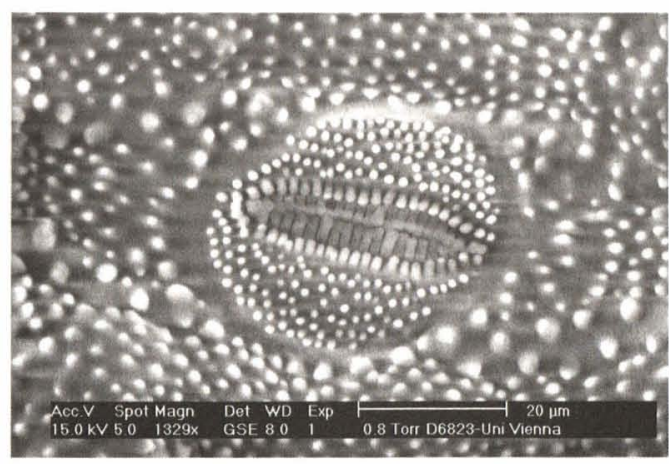

Fig. 6: E. palustre, subsidiary cells with pilulae scattered on the surface, distinct margin absent (SEM).

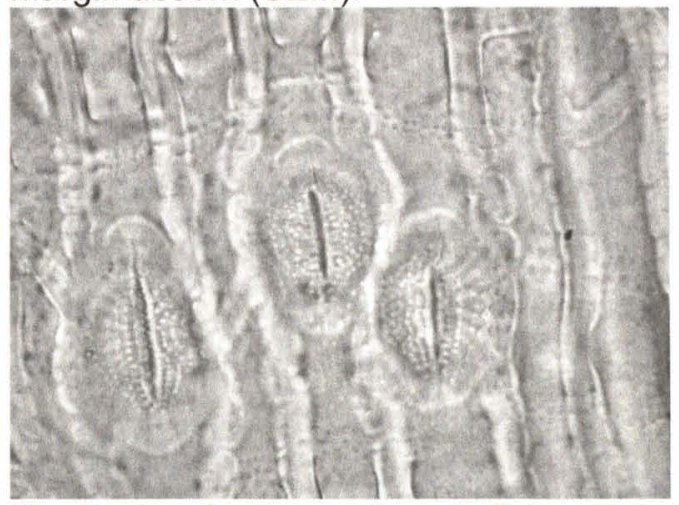

Fig. 8: E. palustre, scattered pilulae (light microscope)
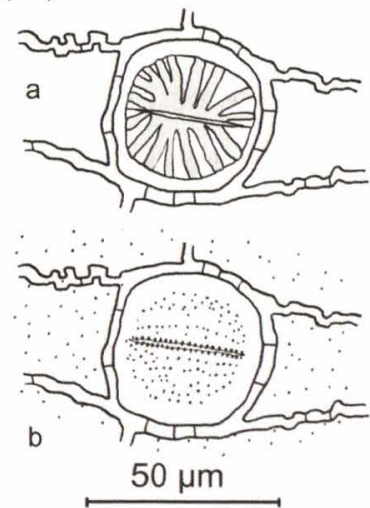

Fig. 10: E. palustre, stomium; a) focus deep; b) focus high 


\section{Ridges}

The most striking character of the ridges is the shape of papillae. Two general types of papillae can be found observing the ridges in lateral longitudinal view: a) one epidermis cell is part of at least two papillae; $b$ ) each papilla consists of a single cell. They may be arranged in axial rows (prevailing type, e.g. E. hyemale, $E$. sylvaticum), accumulated in horizontal bars (e.g. E. palustre) or two horizontally adjacent papillae form a bicellular structure (e.g. E. pratense main stem).

\section{Subgenus Hippochaete}

On the ridges of $E$. hyemale the papillae are arranged in two close parallel axial rows. They consist of heavily thickened and pitted cells. At the projections a considerably thick cuticle is superimposed. Cell borders are hardly discernible in longitudinal sections (Fig. 11, a). The ridges of $E$. variegatum are not acuminated, they resemble a trapezoid in transverse section. At both edges of the top surface the papillae are arranged in an axial row. Seen in longitudinal lateral view they consist either of a single cell or one epidermal cell is part of several papillae (Fig. $11, b)$. The longitudinal view of the papillae of $E$. ramosissimum is very similar to $E$. variegatum (Fig. 11, c), but in contrast the papillae form horizontal bands.

\section{Subgenus Equisetum}

The main stems of $E$. arvense and $E$. telmateia show only low papillae, the dividing cell wall is situated directly beneath the tip or slightly aside (Fig. 11, d, Fig., 12 and Fig. 14); the branches of $E$. arvense are characterized by the well known often nearly rectangular symmetrically divided bicellular papillae (Fig. 11, e and Fig. 16). A similar type is found on the branches of $E$. fluviatile, however the dividing cell wall is located mostly asymmetric (Fig. 11, i). Papillae consisting of two cells occur also on the branches of E. telmateia, however their shape is asymmetric, the proximal side is gently inclined, the distal side is hooked (Fig. 11, j).

An undulated surface is characteristic for the main stem of $E$. fluviatile and the branches of $E$. pratense and $E$. sylvaticum, where each epidermal cell shows 
several indentations and swells (Fig. 11, h).

Unicellular papillae in the typical sense occur on the ridges of the main stem of E. sylvaticum, they stand apart and reach a length of about $80 \mu \mathrm{m}$ (Fig. 11, k). In E. palustre (main stem) the papillae are linked to horizontal aggregates with a smooth surface (Fig. 11, f, Fig. 13 and Fig. 15).

The papillae of the main stem of E. pratense are bicellular, the two cells are arranged at right angle to the axis. Therefore these papillae seem to consist of a single cell only when observed in longitudinal lateral view in the light microscope (Fig. 11, g and Fig. 17). The length of the papillae varies considerably.

In powdered material the ridges of main stems will be seen frequently in surface view. The projections of the papillae may pretend the presence of cell borders. On the ridges of the main stem of $E$. arvense the papillae frequently form short elongated groups at right angle to the epidermal cells (Fig. 14). The smooth surface of the horizontal bands of papillae in E. palustre are clearly discernible in the light microscope (Fig. 15).

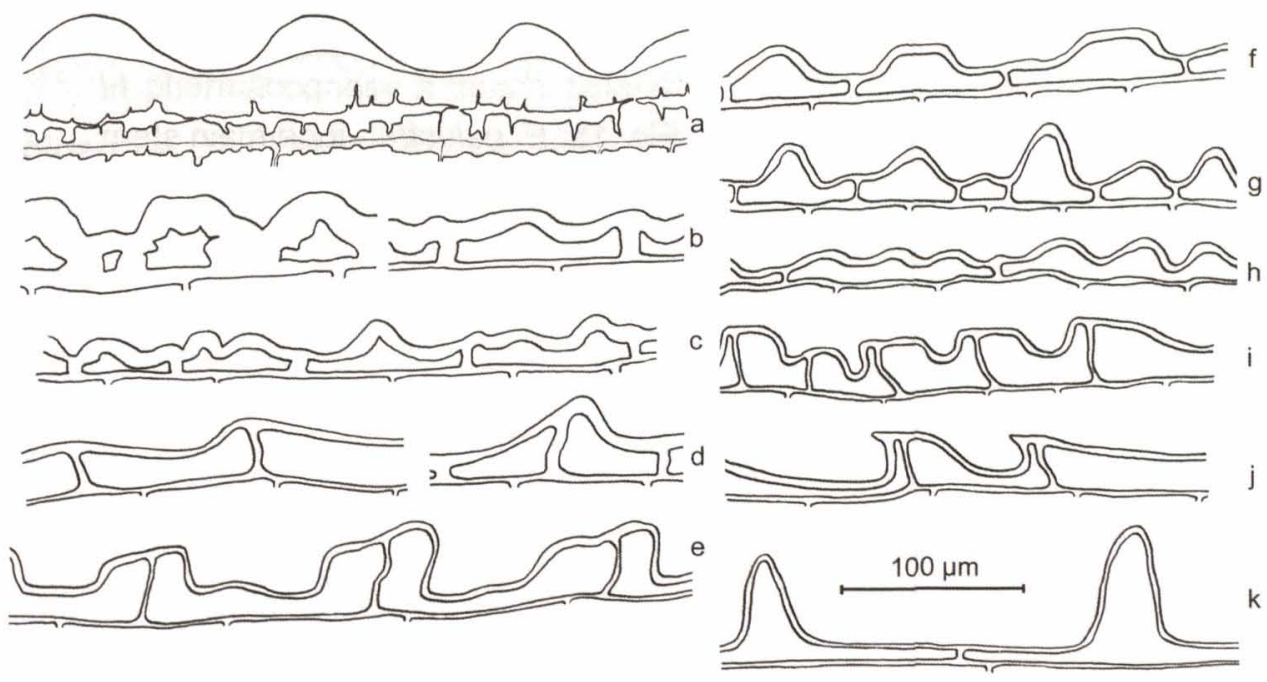

Fig. 11: Papillae on the ridges of species of the genus Equisetum; a) E. hyemale; b) E. variegatum; c) E. ramosissimum; d) E. arvense main stem (identical for E. telmateia main stem); e) E. arvense branch; f) E. palustre main stem and branch; g) E. pratense main stem; h) E. pratense branch, E. sylvaticum branch, $E$. fluviatile main stem; i) E. fluviatile branch; j) E. telmateia branch; k) E. sylvaticum main stem. 


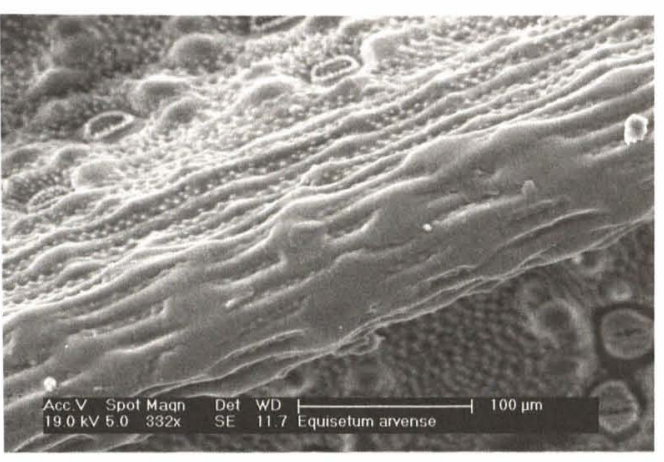

Fig. 12: E. arvense, ridge main stem (SEM)

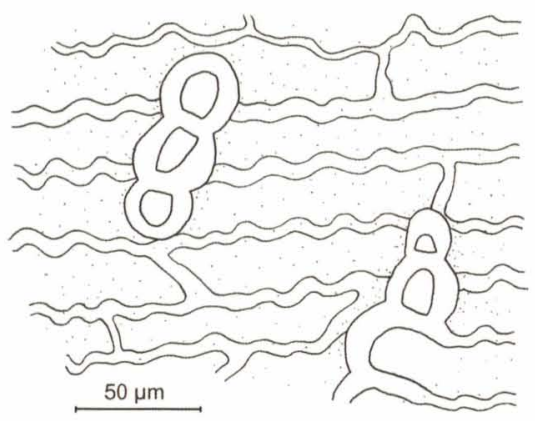

Fig. 14: E. arvense, ridge main stem (light microscope)

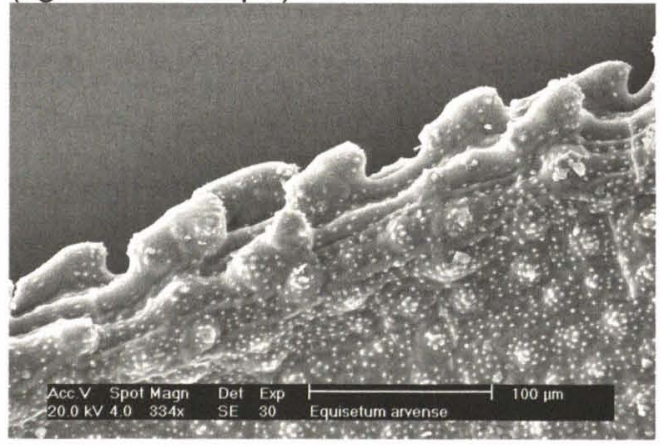

Fig. 16: E. arvense, ridge branch (SEM)

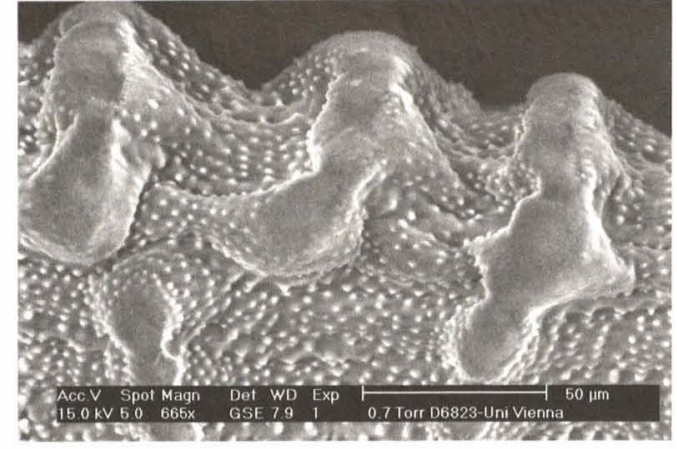

Fig. 13: E. palustre, ridge main stem (SEM)

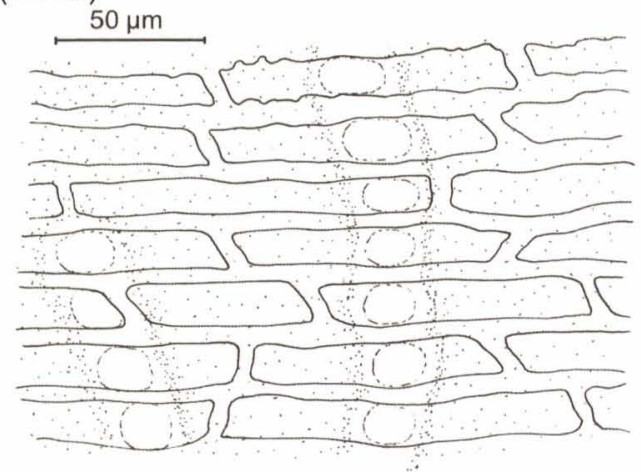

Fig. 15: E. palustre, ridge main stem (light microscope)

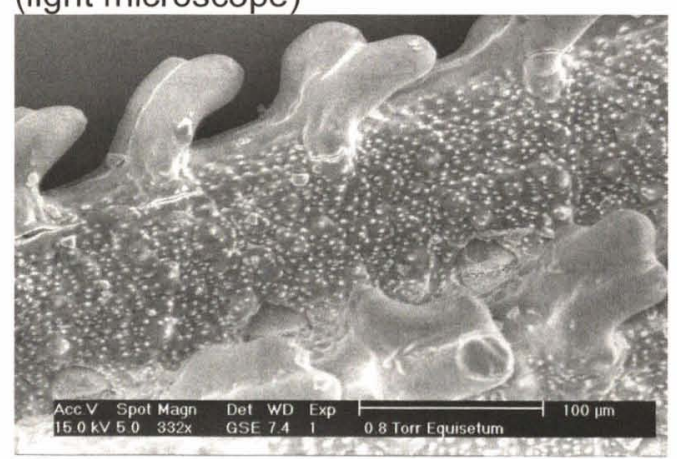

Fig. 17: E. pratense, ridge main stem (SEM) 


\section{Discussion}

The genus Equisetum and the difficult identification of the species challenged scientists at any times, therefore many details of the anatomy of members of the genus Equisetum are already published [e.g. 2, 3, 4], but mostly with respect to taxonomy and relationship of the species. For pharmaceutical purposes two aspects are essential: a) an identification should be possible even in powdered material; b) the methods should be simple and available to everybody involved in the proof of crude drugs. Since the characters mentioned in the monograph of the European Pharmacopoeia are too general for this purpose we initiated a search for reliable details.

The method of choice is light microscopy, however, the silica pilulae, the mamillae on epidermal cells as well as the arrangement of papillae on the ridges are hardly discernible. A more complex method for detection of surface characters is SEM. Therefore we studied the epidermis of main stems and of branches of all major Central European species by SEM and tried to recover promising details in the light microscope.

In pharmacognosy a mostly ignored character are the silica pilulae on the epidermis, particularly on the subsidiary cells of the stomata. Usually these structures are made visible with ash-preparations [5], which are not common in the proof of herbal drugs. The images from the SEM allowed a systematic overview of the types of distribution of the pilulae. Provided that optimal contrast is set with the aperture diaphragm of the light microscope, these pilulae are discernible within a routine control. The size of the stomata as well as the shape of the ridges in the subsidiary cells are too variable in order to serve as characters for discrimination of species.

The combination of the distribution of the pilulae on the subsidiary cells with the arrangement of stomata on the stems allow a nearly unambiguous identification of fragments in a powder. Only exception: the branches of $E$. arvense and $E$. fluviatile are very similar when the fragments are very small. 
More emphasis in the microscopy of Equisetum has been laid on the papillae of the ridges, but most authors focus on the differentiation between $E$. arvense and E. palustre only. Schier et al. [7] presented drawings of the papillae of nearly all relevant species, unfortunately no differentiation between main stem and branches was done. In addition the arrangement of the papillae on the ridges remained unconsidered, some drawings differ considerably from our material. The papillae in lateral longitudinal view seem to be highly characteristic, particularly when combined with their arrangement on the ridges. The most similar parts are the branches of $E$. arvense and $E$. fluviatile. These species differ in their pattern of flavonoids, the presence of E. fluviatile could be detected by TLC [5].

An improved monograph of the European Pharmacopoeia should consider in addition to the presence of ridges on the subsidiary cells also the details of the silica pilulae on the subsidiary cells (forming a distinct margin), the number of rows of stomata per flank (2-4), and the presence of two types of papillae (low 2-celled on main stem, rectangular 2-celled on branches).

\section{Proposal for the European Pharmacopoeia:}

Fragments of the epidermis in surface view, composed of rectangular cells with wavy walls and paracytic stomata in 2-4 rows, the subsidiary cells are in plane with the epidermis and cover the guard cells, they have cell wall thickenings in the shape of conspicuous radial ridges, small silica pilulae are scattered on the surface and form a distinct margin; papillae on the ridges 2-celled, on the main stem low, on the branches large and rectangular. Fragments of large-celled parenchyma, fibres and vessels with spiral or annular wall thickening.

However, the best description of a powder doesn't allow a proof of identity and purity with the same accuracy like a proof of unmilled material. Even when the Pharmacopoeia claims to powder the sample prior to microscopic examination the identity and purity of a sample should assured preferably prior to this step, because the highly characteristic papillae can be clearly seen even with a stereomicroscope without a specific sample preparation. 


\section{Key for fragments with stomata}

1 Stomata absent

E. telmateia

$1^{*}$ Stomata present

(main stem)

2 Stomata deepened into the surface

3 Conspicuous rows of mamillae in grooves between stomata, pilulae rare

E. variegatum

$3^{*}$ Low horizontal bars in grooves between stomata, E. hyemale pilulae rare

$3^{* *}$ Epidermis with mamillae und abundant pilulae E. ramosissimum

$2^{*} \quad$ Stomata in plane with surface

4 Pilulae forming a distinct margin around the subsidiary cells

5 Stomata in a single axial row (rarely in $2 \quad$ E. sylvaticum rows)

$5^{*}$ Stomata 2 or more rows
6 Stomata in 2-3 rows
E. arvense
$6^{*}$ Stomata in numerous rows
E. fluviatile

4* Pilulae dense at pore, regularly scattered on the subsidiary cells, distinct margin absent
7 Stomata in a single axial row
E. pratense

$7^{*}$ Stomata in more rows

8 Stomata horizontally separated by bars of

E. palustre papillae

8* Horizontal bars absent

E. telmateia

(branch)

\section{Experimental}

\section{Plant material}

Investigations were done using authenticated herbarium specimens, vouchers are deposited in the herbarium of the Institute of Botany, Univ. Vienna (herbarium WU, $E$. pratense, E. ramosissimum, E. variegatum p.p.) and in the herbarium of the Dept. of Pharmacognosy, Univ. Vienna (all other species).

List of investigated species (number in brackets = number of individuals)

Subgenus Hippochaete: E. variegatum (3), E. hyemale (8), E. ramosissimum (3)

Subgenus Equisetum: E. fluviatile (5), E. palustre (10), E. sylvaticum (10), E. pratense (3), E. telmateia (5), E. anvense (20). 


\section{Microscopic techniques}

Light microscopy: paradermal sections of the main stem and of branches for surface view, clearing by boiling in $60 \%$ chloral hydrate solution.

Scanning electron microscopy: Philips XL 30 ESEM; High vacuum mode: samples of dry herbarium specimens sputtered with gold; Low vacuum mode: samples of dry herbarium specimens without sputtering.

\section{Acknowledgment}

We are thankful to Dr. Walter Till, Dept. for Systematics and Evolution, Faculty Center Botany, Univ. Vienna, for the permission to study material of $E$. pratense, $E$. variegatum and $E$. ramosissimum of the herbarium WU.

\section{References}

[1] Dostal J in Conert H J, Hamann U, Schultze-Motel W, Wagenitz G, editors.

Equisetaceae.

Illustrierte Flora von Mitteleuropa. Vol 1/1, $3^{\text {rd }}$ ed. Berlin-Hamburg: Verlag

Paul Parey, 1984: 54-79.

[2] Kaufman P B, Bigelow W C, Schmid R, Ghosheh N S

Electron microprobe analysis of silica in epidermal cells of Equisetum.

Amer. J. Bot. 1971; 58: 309-316.

[3] Hauke R L

A taxonomic monograph of Equisetum subgenus Equisetum.

Nova Hedwigia 1978; 30: 385-455.

[4] Page C N

An assessment of inter-specific relationships in Equisetum subgenus

Equisetum.

New Phytol. 1972; 71: 355-369.

[5] Veit M

Untersuchungen zur Biologie sowie Akkumulation und Analytik von

Sekundärstoffen der Equiseten unter besonderer Berücksichtigung von

Equisetum arvense L.

Dissertation Univ. Würzburg 1990.

[6] Czygan F-C in Wichtl M, editor.

Equiseti herba.

In: Teedrogen und Phytopharmaka. $4^{\text {th }}$ ed. Stuttgart: Wissenschaftliche Verlagsgesellschaft mbH, 2002: 195-199.

[7] Schier W, Lube B

Die mikroskopische Unterscheidung der Equisetum-Arten.

Deutsche Apoth. Ztg. 1984; 124: 797-799. 